\title{
Effect of A Kappa-opioid Receptor Agonist U50488H Given at Early Reperfusion Phase in Isolated Rat Hearts
}

\author{
Departments of Anesthesiology and Pain Medicine, and *Internal Medicine, School of Medicine, Keimyung University, Daegu, Korea
}

Yong Cheol Lee, M.D., Young Ho Jang, M.D., Jin Mo Kim, M.D., Ae Ra Kim, M.D., Chan Jin Kim, M.D., and Yoon Nyun Kim, M.D.*

Background: The experiment was performed to determine the role of $\kappa$-opioid receptor (OR) agonist U50488H given at early reperfusion.

Methods: Isolated hearts were subjected to 30 minutes of regional ischemia and 120 minutes of reperfusion. Hearts were assigned randomly to one of the three groups: 1) Control ( $\mathrm{n}=9), 2) \mathrm{U50}-1(\mathrm{n}=8) ; 1 \mu \mathrm{M}$ of U50488H, and 3) U50-10 (n $=8) ; 10 \mu \mathrm{M}$ of U50488H. U50488 was perfused for a period of $5 \mathrm{~min}$ before and $30 \mathrm{~min}$ after reperfusion.

Results: U50488H significantly reduced infarct size as a percentage of ischemic area (12.2 $\pm 1.9 \%$ in U50-1 and $7.2 \pm 1.7 \%$ in U50-10, P $<0.001)$ compared to the control hearts $(27.2 \pm 1.2 \%)$. After $2 \mathrm{hrs}$ of reperfusion, left ventricular developed pressure was significantly recovered by U50488H $(62.6 \pm 5.7 \%$ in U50-1 and $68.6 \pm 4.7 \%$ in U50-10, P $=0.018$ and 0.002 , respectively) compared to the control $(46.3 \pm 4.4 \%)$. Rate-pressure product was improved by $10 \mu \mathrm{M} \mathrm{U} 50488 \mathrm{H}(62.3 \pm 5.5 \%, \mathrm{P}=0.007)$ but not by $1 \mu \mathrm{M}$ U50488H $(50.0 \pm 4.1 \%)$ compared to the control $(44.7 \pm 4.5 \%)$. U50488H significantly increased the $+\mathrm{dP} / \mathrm{dt}_{\max }$ (77.9 $\pm 5.5 \%$ in U50-1 and $78.0 \pm 4.3$ in U50-10, $\mathrm{P}=0.005$ and 0.001 vs. control, respectively). The $-\mathrm{dP} / \mathrm{dt}_{\min }$ also improved by $10 \mu \mathrm{M}$ U50488H $(64.7 \pm 4.8 \%, \mathrm{P}=0.003)$ compared to control $(47.0 \pm 2.7 \%)$.

Conclusions: U50488H given at early reperfusion phase reduces both infarct size and myocardial stunning in isolated rat hearts. (Korean J Anesthesiol 2008; 54: S 29 34)

Key Words: ischemia, myocardium, opioid receptor, reperfusion.

\section{INTRODUCTION}

Opioids have been widely used in the anesthesia field as anesthetic adjuncts or for pain control. Because pretreatment is seldom possible in an acute myocardial infarction, pharmacological therapies targeting reperfusion has generated considerable recent interest. In this regard, opioids may play a key strategic role because these drugs are widely used in clinical field and can protect against post-ischemic myocardial injury at the time of reperfusion. ${ }^{1)}$

Based on binding studies, there is evidence that both $\delta$ - and $\kappa$-opioid receptors (OR) are located in the myocardium. ${ }^{2,3)}$ It has previously been demonstrated that the activation of OR by

Received : January 17, 2008

Corresponding to : Young Ho Jang, Department of Anesthesiology and Pain Medicine, School of Medicine, Keimyung University, 194, Dongsan-dong, Jung-gu, daegu 700-712, Korea. Tel: 82-53-250-7287, Fax: 82-53-250-7240, E-mail: weonjo@ hotmail.com ischemic preconditioning (IPC) or by opioid-induced pharmacological pretreatment provides cardioprotection against ischemiareperfusion (I/R) injury via activation of the $\delta$-OR subtypes, especially the $\delta_{1}-\mathrm{OR}^{4-6)}$ However, the cardioprotective role of $\kappa$-OR remains unclear and there continues to be controversy regarding its role in myocardial $\mathrm{I} / \mathrm{R}$ injury. ${ }^{6-9)}$ Recently, Wang et al. $^{10)}$ demonstrated that ischemic postconditioning (Post-C) improved cardiodynamics in isolated rat hearts. They suggested that the functional recovery by Post-C was induced via activation of $\kappa$-OR and opening of mitochondrial $\mathrm{K}_{\mathrm{ATP}}\left(\mathrm{mK}_{\mathrm{ATP}}\right)$ channels. Therefore, it is highly suggested that the direct treatment of $\mathrm{U} 50488 \mathrm{H}$, a selective $\kappa$-OR agonist, given at early reperfusion might also improve cardiodynamic parameters in $\mathrm{I} / \mathrm{R}$ induced hearts.

The objective of this study was to investigate the protective effect of U50488H on infarct limitation and post-reperfusion contractile recovery during the reperfusion phase in isolated perfused rat hearts. 


\section{MATERIALS AND METHODS}

The experimental procedures and protocols used in this study were reviewed and approved by our Institutional Animal Care and Use Committee, 2007.

\section{Langendorff isolated heart perfusion preparation}

Male Wistar rats weighing 280-320 g were obtained from Korea Taconic Co., Republic of Korea. They received 100 $\mathrm{mg} / \mathrm{kg}$ of pentobarbital sodium and $300 \mathrm{IU}$ of heparin intraperitoneally. Hearts were isolated and perfused as described in our previous report. ${ }^{11)}$ In brief, a midline thoracotomy was performed and the heart was quickly mounted on a Langendorff apparatus by the aortic root. The heart was perfused with modified Krebs-Henseleit (KH) solution containing (in $\mathrm{mM}$ ) 118.5 NaCl, 4.7 KCl, $1.2 \mathrm{MgSO}_{4}, 1.8 \mathrm{CaCl}_{2}, 24.8 \mathrm{NaHCO}_{3}$, $1.2 \mathrm{KH}_{2} \mathrm{PO}_{4}$, and 10 glucose. All these chemicals were obtained from Sigma-Aldrich Chemical, USA. The solution was filtered through a Nargene $2.0 \mu \mathrm{m}$ microfilter (Nalge Nunc International Corp., USA) and was equilibrated with $95 \% \mathrm{O}_{2} / 5 \% \quad \mathrm{CO}_{2}$ for $30 \mathrm{~min}$ before the experiment and $\mathrm{pH}$ maintained at approximately 7.4. The whole perfusion system was heated to $38^{\circ} \mathrm{C}$ by means of water jacketing. Perfusion was performed under a hydrostatic pressure of $100 \mathrm{cmH}_{2} \mathrm{O}$ by adjusting the height of the reservoir.

\section{Making a myocardial regional ischemia-repefusion model}

In order to induce myocardial regional ischemia, the proximal portion of left coronary artery (LCA) was first localized between the left atrial appendage and the right ventricular outflow tract. This was then followed by the passage of a 4-0 polypropylene suture around the major trunk of the LCA or its prominent branches. The ends of the thread were passed through a small PE50 tube to form a snare. All hearts were then allowed to stabilize for at least 30 minutes. Ischemia was induced by pulling the snare and then fixing it by clamping the tubing with a small hemostat. Myocardial ischemia was confirmed by regional cyanosis, a substantial decrease in left ventricular developed pressure (LVDP), and a fall in coronary flow (CF). Reperfusion was initiated by releasing the ends of the suture. All hearts were subjected to 30 minutes of regional ischemia and 120 minutes of reperfusion.

\section{Assessment of cardiac function}

In isolated hearts, an air-bubble free, KH buffer-filled latex balloon connected to a pressure transducer with tubing was inserted into the left ventricle through the left atrial appendage. Balloon volume was adjusted to give a left ventricular enddiastolic pressure (LVEDP) of 5-10 $\mathrm{mmHg}$ at the beginning of the experiment and was kept constant throughout the experiment. LVDP was calculated as the difference between left ventricular systolic pressure (LVSP) and LVEDP. CF was measured by a timed collection of the perfusate drippings from the right heart into a graduated cylinder.

Hemodynamic data were continuously recorded with the MP150 system (BIOPAC Systems Inc., USA). The rate-pressure product (RPP) was calculated as the LVDP $\times$ heart rate $(\mathrm{HR})$. The maximum and minimum of first derivative of left ventricular pressure $\left(+\mathrm{dP} / \mathrm{dt}_{\max }\right.$ and $\left.-\mathrm{dP} / \mathrm{dt}_{\min }\right)$ were analyzed using analysis software (Acqknowledge, version 3.9.0., BIOPAC Systems Inc., CA).

\section{Experimental protocol}

Hearts were randomly divided into three groups: (1) Control; no intervention either before or after LCA occlusion, (2) U50-1; $1 \mu \mathrm{M}$ of $\mathrm{U} 50488 \mathrm{H}$, and (3) $\mathrm{U} 50-10 ; 10 \mu \mathrm{M}$ of $\mathrm{U} 50488 \mathrm{H}$ (Fig. 1). A standard selective $\kappa$-OR agonist U50488H (Tocris Bioscience, USA) was perfused for a period of $5 \mathrm{~min}$ before and $30 \mathrm{~min}$ after reperfusion. U50488H was dissolved in distilled water and prepared in stock solution. The final concentrations, which did not exceed $2.5 \mathrm{mM}$, were stored at $4^{\circ} \mathrm{C}$ according to the manufacturer's guidance. On the day of each experiment,

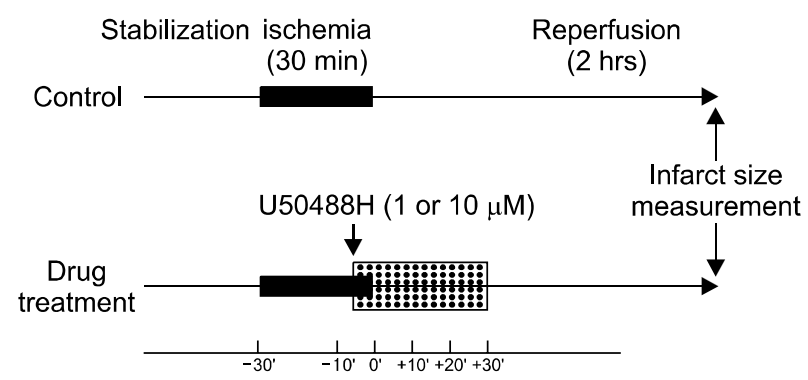

Fig. 1. Experimental protocol. For measurement of hemodynamic data and infarct size by $\kappa$-opioid receptor activation, isolated rat hearts are exposed to $30 \mathrm{~min}$ ischemia followed by $2 \mathrm{hrs}$ reperfusion. Two concentrations of $\kappa$-opioid receptor agonist U50488H $(1$ and $10 \mu \mathrm{M})$ are perfused for a period of $5 \mathrm{~min}$ before and 30 min after reperfusion (hatched rectangle) 
Table 1. Morphometrics for Isolated Rat Hearts

\begin{tabular}{lcccccc}
\hline \multicolumn{1}{c}{ Group } & $\begin{array}{c}\text { Body weight } \\
(\mathrm{gm})\end{array}$ & $\begin{array}{c}\text { Heart weight } \\
(\mathrm{gm})\end{array}$ & $\begin{array}{c}\text { LV volume } \\
\left(\mathrm{cm}^{3}\right)\end{array}$ & $\begin{array}{c}\text { AAR volume } \\
\left(\mathrm{cm}^{3}\right)\end{array}$ & $\begin{array}{c}\text { AAR/LV } \\
(\%)\end{array}$ & $\begin{array}{c}\text { AN volume } \\
\left(\mathrm{cm}^{3}\right)\end{array}$ \\
\hline Control $(\mathrm{n}=9)$ & $305.0 \pm 5.8$ & $1.42 \pm 0.02$ & $0.519 \pm 0.020$ & $0.303 \pm 0.014$ & $60.8 \pm 2.9$ & $0.082 \pm 0.004$ \\
U50-1 $(\mathrm{n}=8)$ & $307.8 \pm 9.8$ & $1.42 \pm 0.03$ & $0.498 \pm 0.019$ & $0.291 \pm 0.020$ & $59.2 \pm 5.1$ & $0.036 \pm 0.005^{*}$ \\
U50-10 $(\mathrm{n}=8)$ & $301.9 \pm 4.8$ & $1.40 \pm 0.01$ & $0.486 \pm 0.029$ & $0.279 \pm 0.019$ & $59.2 \pm 5.7$ & $0.022 \pm 0.006^{*}$ \\
\hline
\end{tabular}

Values are mean \pm SEM. $\mathrm{n}$ : number of hearts. LV: left ventricle, AAR: area at risk, AN: area at necrosis, U50-1: $1 \mu \mathrm{M}$ U50488H, U50-10: $10 \mu \mathrm{M}$ U50488H. There were no differences in body weight, heart weight, volumes of LV and AAR, and AAR/LV among groups. *: $\mathrm{P}<0.001$ vs. Control.

the compound was diluted with $\mathrm{KH}$ solution to the required final concentrations.

\section{Determination of area at risk and infarct size}

At the end of each experiment ( 2 hrs after reperfusion), the area at risk (AAR) and area at necrosis (AN) were measured as described in our previous study. ${ }^{11)}$ In brief, the LCA perfusion circuit was reoccluded, and diluted fluorescent polymer microspheres with 2-9 $\mu \mathrm{m}$ diameter (Duke Scientific Corp., USA) were infused to demarcate the AAR as the tissue without fluorescence. The hearts were weighed, frozen at $-20^{\circ} \mathrm{C}$ for $1-$ $3 \mathrm{hrs}$, and cut into $2 \mathrm{~mm}$ thick transverse slices using a rat heart slice matrix (Zivic Instruments, USA). The slices were incubated in $1 \%$ 2,3,5-triphenyltetrazolium chloride (TTC, Sigma-Aldrich Chemical, USA) in sodium phosphate buffer $(\mathrm{pH}=$ 7.4 ) at $37^{\circ} \mathrm{C}$ for $20 \mathrm{~min}$. The slices were immersed in $10 \%$ formalin to enhance the contrast between viable (red) and necrotic (pale) tissue and then compressed to a uniform $2 \mathrm{~mm}$ thickness by placing them (basal side) between two glass plates separated by a $2 \mathrm{~mm}$ space. The myocardial AAR was identified by illuminating the slices with U.V. light. The infarcted (unstained) and risk (no fluorescent area) zone regions were traced on a clear acetate transparent sheet and quantified with the UTHSCSA Image Tool 3.0 version. Volumes of the left ventricle, infarct zone, and risk zone were calculated by multiplying each area with slice thickness and summing the products. Infarct volume was expressed as a percentage of the AAR volume. All measurements were performed in a blinded fashion.

\section{Statistical analysis}

All values were expressed as means \pm SEM. Data analysis was performed with SPSS 13.0 version. Data were analyzed using one-way analysis of variance with the Least Significant Difference test. Differences were considered to be statistically

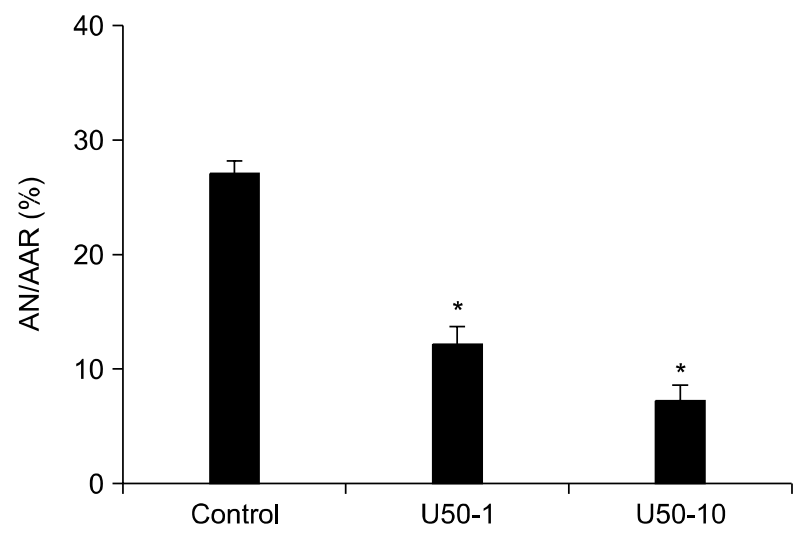

Fig. 2. Area at necrosis (AN) as percentage of area at risk (AAR) as evaluated by triphenyltetrazolium chloride staining following 30 min regional ischemia and $2 \mathrm{hrs}$ reperfusion in isolated rat heart model. Rat hearts were subjected to control and treated with 1 (U50-1) or $10 \mu \mathrm{M}$ (U50-10) of U50488H. Both concentrations of $\mathrm{U} 50488 \mathrm{H}$ given at early reperfusion phase significantly decreases AN/AAR. Values are expressed as mean \pm SEM. *: $\mathrm{P}<0.001$ vs. control.

significant when $\mathrm{P}$ values were less than 0.05 .

\section{RESULTS}

A total of 28 rat hearts were used for this experiment. All hearts were perfused within 30-40 seconds after excision. Three hearts were excluded from data analysis for the following reasons: a CF $>18 \mathrm{ml} / \mathrm{min}$ (1), LVDP $<80 \mathrm{mmHg}$ (1), and HR $<250$ beats/min (1) during the stabilization period. Therefore, we report the data for 25 successfully completed experiments ( 9 in Control, 8 in U50-1, and 8 in U50-10, respectively).

There were no significant group differences with respect to body weight, heart weight, and volumes of left ventricle and AAR (Table 1). As shown in Fig. 2, infarct size in the control hearts was $27.2 \pm 1.2 \%$ of the AAR. Both concen- 
Table 2. Baseline Coronary Flow and Hemodynamic Data

\begin{tabular}{ccccccc}
\hline Group & CF & HR & LVDP & RPP & $+\mathrm{dP}_{\mathrm{dt}} t_{\max }$ & $-\mathrm{dP}_{\mathrm{dt}}$ \\
\hline Control $(\mathrm{n}=9)$ & $14.0 \pm 0.62$ & $83.1 \pm 8.1$ & $103.5 \pm 8.9$ & $29.1 \pm 2.3$ & $2.69 \pm 0.15$ & $-2.67 \pm 0.20$ \\
U50-1 $(\mathrm{n}=8)$ & $13.6 \pm 0.92$ & $92.1 \pm 7.1$ & $103.8 \pm 3.8$ & $30.2 \pm 1.0$ & $2.60 \pm 0.10$ & $-2.66 \pm 0.10$ \\
U50-10 $(\mathrm{n}=8)$ & $14.0 \pm 1.02$ & $92.1 \pm 7.1$ & $103.8 \pm 3.8$ & $30.2 \pm 1.0$ & $2.60 \pm 0.10$ & $-2.66 \pm 0.10$ \\
\hline
\end{tabular}

Values are mean \pm SEM. $\mathrm{n}$ : number of hearts. CF: coronary flow (ml/min), HR: heart rate (beats/min), LVDP: left ventricular developed pressure $(\mathrm{mmHg}), \mathrm{RPP}$ : rate-pressure product $\left(\mathrm{mmHg} / \mathrm{min} / 10^{3}\right),+\mathrm{dP} / \mathrm{dt}_{\max }$ : maximum positive left ventricular pressure derivative $\left(\mathrm{mmHg} / \mathrm{s} / 10^{3}\right)$, $-\mathrm{dP} / \mathrm{dt}_{\min }$ : minimum negative left ventricular pressure derivative $\left(\mathrm{mmHg} / \mathrm{s} / 10^{3}\right), \mathrm{U} 50-1: 1 \mu \mathrm{M} \mathrm{U} 50488 \mathrm{H}, \mathrm{U} 50-10: 10 \mu \mathrm{M} 50488 \mathrm{H}$. There were no differences in baseline $\mathrm{CF}$ and hemodynamics among groups.
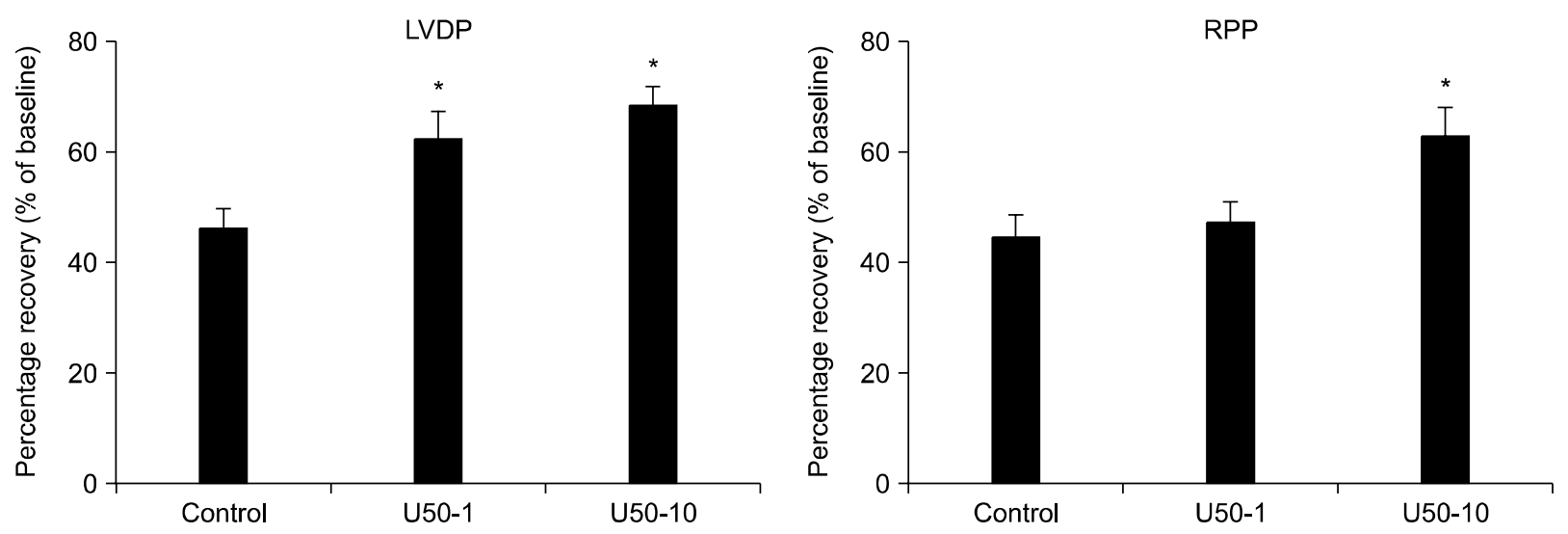

Fig. 3. Recovery of the left ventricular developed pressure (LVDP) and rate-pressure product (RPP) after 2 hrs reperfusion in isolated rat hearts. Rat hearts were subjected to control and treated with 1 (U50-1) or $10 \mu \mathrm{M}$ (U50-10) of U50488H. U50488H treatment at reperfusion phase significantly increases the LVDP and RPP. Value are expressed as means \pm SEM. *: P $<0.05$ vs. control.

trations of a $\kappa$-OR agonist U50488H given at early reperfusion phase significantly reduced myocardial infarction $(12.2 \pm 1.9 \%$ in U50-1 and $7.2 \pm 1.7 \%$ in U50-10, $\mathrm{P}<0.001$ vs. control).

The baseline hemodynamic data are summarized in Table 2 . $\mathrm{CF}$ and hemodynamic indexes concerning HR, LVDP, RPP, + $\mathrm{dP} / \mathrm{dt}_{\max }$, and $-\mathrm{dP} / \mathrm{dt}_{\min }$ were comparable in all groups under baseline conditions. The changes in LVDP and RPP after 2 hrs of reperfusion are presented in Fig. 3. LVDP was decreased to $46.3 \pm 4.4 \%$ after 2 hrs of reperfusion compared to baseline value in control hearts. U50488H treatment at reperfusion phase significantly recovered the LVDP compared to the control hearts $(62.6 \pm 5.7 \%$ in U50-1, $\mathrm{P}=0.018,68.6$ $\pm 4.7 \%$ in U50-10, $\mathrm{P}=0.002$ ). RPP in the control hearts was decreased to $44.7 \pm 4.5 \%$ after $2 \mathrm{hrs}$ of reperfusion. The attenuation of RPP was improved by $10 \mu \mathrm{M}$ U50488H $(62.3 \pm$ $5.5 \%, \mathrm{P}=0.007)$ but not by $1 \mu \mathrm{M}$ U50488H $(50.0 \pm 4.1 \%)$.

The changes in the recovery of the first derivative of left ventricular pressure after $2 \mathrm{hrs}$ reperfusion are shown in Fig. 4. After $2 \mathrm{hrs}$ of reperfusion, $+\mathrm{dP} / \mathrm{dt}_{\max }$ and $-\mathrm{dP} / \mathrm{dt}_{\min }$ in the control hearts were decreased to $49.2 \pm 3.6 \%$ and $47.0 \pm$
$2.7 \%$ compared to baseline levels, respectively. Both concentrations of $\mathrm{U} 50488 \mathrm{H}$ significantly increased $+\mathrm{dP} / \mathrm{dt}_{\max }(77.9 \pm$ $5.5 \%$ in U50-1 and $78.0 \pm 4.3 \%$ in U50-10, $\mathrm{P}=0.005$ and 0.001 vs. control, respectively). The treatment of $10 \mu \mathrm{M} \mathrm{U} 50488 \mathrm{H}$ effectively improved $-\mathrm{dP} / \mathrm{dt}_{\min }(64.7 \pm 4.8 \%, \mathrm{P}=0.003)$ compared to the control hearts $(47.0 \pm 2.7 \%)$.

\section{DISCUSSION}

There remains controversy regarding the role of $\kappa$-OR agonists in myocardial $\mathrm{I} / \mathrm{R}$ injury. Previous studies have demonstrated that pharmacological preconditioning with a $\kappa$-OR agonist bremazocin increased infarct size ${ }^{9)}$ and another $\kappa$-OR agonist $\mathrm{U} 50488 \mathrm{H}$ exacerbated ischemic-reperfusion arrhythmias following coronary occlusion in the isolated rat hearts. ${ }^{12)}$ Conversely, Peart et al. $^{7)}$ demonstrated that exogenously application of three different $\kappa$-OR agonists (U50488H, ICI204448, and BRL52537) $10 \mathrm{~min}$ before the onset of ischemia reduced infarct size in intact myocardial infarction rat models. Taken together, these results do not completely rule out roles for $\kappa$-OR agonists in 

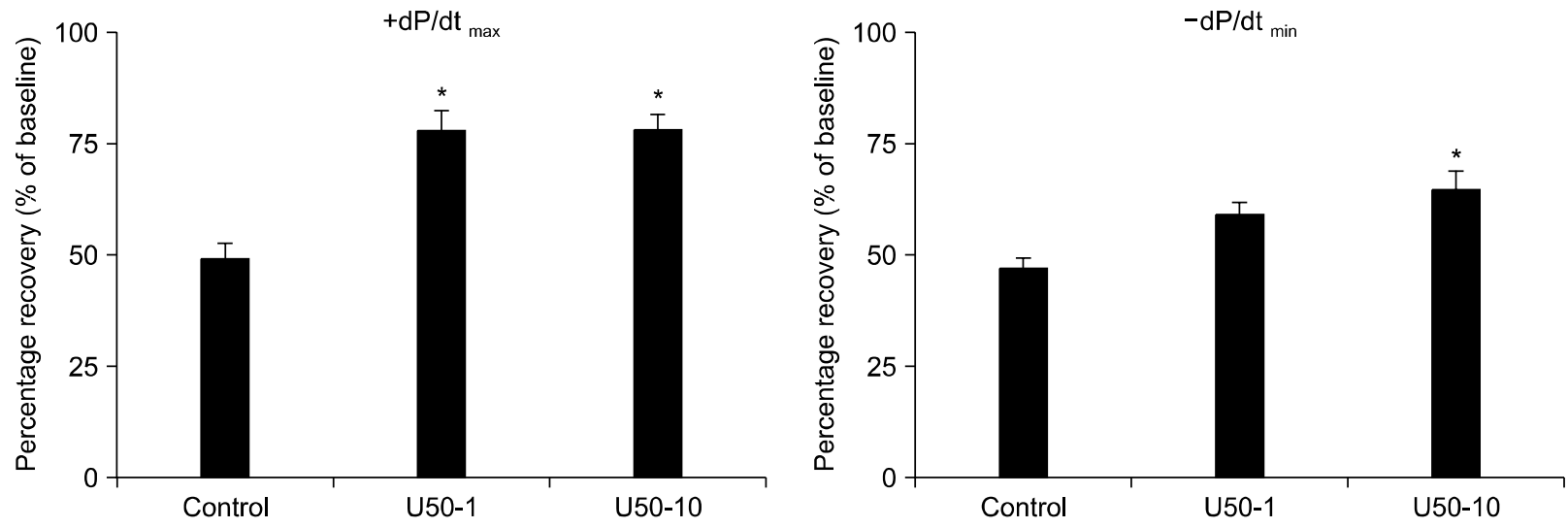

Fig. 4. Recovery of the maximum $\left(+\mathrm{dP} / \mathrm{dt}_{\max }\right)$ and minimum $\left(-\mathrm{dP} / \mathrm{dt}_{\min }\right)$ of first derivative of left ventricular pressure after 2 hrs reperfusion in isolated rat hearts. Rat hearts were subjected to control and treated with 1 (U50-1) or $10 \mu \mathrm{M}$ (U50-10) of U50488H. U50488H treatment at reperfusion significantly enhanced the recovery of the $+\mathrm{dP} / \mathrm{dt}_{\max }$ and $-\mathrm{dP} / \mathrm{dt}_{\min }$. Value are expressed as means \pm SEM. ${ }^{*}$ : P $<0.05$ vs. control.

cardioprotection. However, most of the studies to investigate the role of OR agonists in myocardial $\mathrm{I} / \mathrm{R}$ injury thus far were mainly focused on the nonspecific OR agonist or $\delta$-OR agonist. $^{1,13)}$ Furthermore, there is scanty literature that have investigated the effects of a $\kappa$-OR agonist U50488H administered solely at reperfusion.

In our present study, the AN/AAR in control hearts was $27.2 \pm 1.2 \%$. Although the AN/AAR in our control hearts was smaller than those reported by others, ${ }^{1,14)}$ this is in agreement with our recently reported study. ${ }^{15)}$ Although the exact reason for this discrepancy is unknown, differences in the determination of risk and infarct area may account for it. U50488H given at early reperfusion phase was shown to significantly reduce myocardial infarction in our isolated rat hearts. These results are consistent with a recent report by Gross group, ${ }^{16)}$ which showed that either $\delta$ - or $\kappa$-OR agonist administered as a single bolus $5 \mathrm{~min}$ before reperfusion could provide infarct size sparing effects in intact rat heart. Combined with our data, it is strongly suggested that $\kappa-\mathrm{OR}$ agonist U50488H targeting the reperfusion phase may play a role to prevent lethal reperfusion injury.

While treatment of $\kappa$-OR agonists during the reperfusion phase provides anti-infarct effects, little is known about its cardiodynamic effect following reperfusion. Recently, Wang et al. ${ }^{10)}$ reported that Post-C improved the cardiodynamic parameters via activating $\kappa$-OR and $\mathrm{mK}_{\mathrm{ATP}}$ by indirect antagonist study.

Peart and Gross ${ }^{17)}$ reported that U50488H confers cardioprotection with respect to $\mathrm{LVDP},+\mathrm{dP} / \mathrm{dt}_{\max }$, and $-\mathrm{dP} / \mathrm{dt}_{\min }$ in isolated mice hearts undergoing $20 \mathrm{~min}$ global ischemia followed by $45 \mathrm{~min}$ reperfusion. However, it is not clear whether the contractile recovery after reperfusion is caused by the treatment prior to the ischemic period or due to its effects during the reperfusion period in their study (they used $\mathrm{U} 50488 \mathrm{H}$ for $10 \mathrm{~min}$ prior to global ischemia and resumed it at the onset of reperfusion). Therefore, we investigated the functional recovery effects by $\kappa$-OR agonist U50488H targeting only the reperfusion period. Both concentrations of $\mathrm{U} 50488 \mathrm{H}(1$ and $10 \mu \mathrm{M})$ given at early reperfusion phase significantly improved the functional recovery of LVDP, RPP, $+\mathrm{dP} / \mathrm{dt}_{\max }$, and $-\mathrm{dP} / \mathrm{dt}_{\min }$ after 2 hrs of reperfusion in our study. The LVDP recovered to more than $80 \%$ of its baseline levels by $\mathrm{U} 50488 \mathrm{H}$. The maximum and minimum of the first derivative of left ventricular pressure were significantly improved up to $46 \%$ compared to control hearts by $\mathrm{U} 50488 \mathrm{H}$ after $2 \mathrm{hrs}$ of reperfusion. The functional recovery was greater in the $10 \mu \mathrm{M} \mathrm{U} 50488 \mathrm{H}$. However, one should take into consideration that the higher concentration may lead to more undesirable effects.

In summary, a $\kappa$-OR agonist U50488H given at early reperfusion could significantly reduce both infarct size and myocardial stunning in isolated rat hearts. These results may benefit future clinical strategies when treating patients with ischemic heart disease.

\section{REFERENCES}

1. Gross ER, Hsu AK, Gross GJ: Opioid-induced cardioprotection occurs via glycogen synthase kinase $\beta$ inhibition during reper- 
fusion in intact rat hearts. Circ Res 2004; 94: 960-6.

2. Krumins SA, Faden AI, Feuerstein G: Opiate binding in rat hearts: modulation of binding after hemorrhagic shock. Biochem Biophys Res Commun 1985; 127: 120-8.

3. Ventura C, Bastagli L, Bernardi P, Caldarera CM, Guarnieri C: Opioid receptors in rat cardiac sarcolemma: effect of phenylephrine and isoproterenol. Biochim Biophys Acta 1989; 987: 69-74.

4. Okubo S, Tanabe Y, Takeda K, Kitayama M, Kanemitsu S, Kukreja RC, et al: Ischemic preconditioning and morphine attenuate myocardial apoptosis and infarction after ischemiareperfusion in rabbit: role of $\delta$-opioid receptor. Am J Physiol Heart Cric Physiol 2004; 287: H 1786-91.

5. Peart JN, Patel HH, Gross GJ: Delta-opioid receptor activation mimics ischemic preconditioning in the canine heart. J Cardiovasc Pharmacol 2003; 42: 78-81.

6. Schultz JE, Hsu AK, Gross GJ: Ischemic preconditioning in the intact rat heart is mediated by $\delta 1$ but not $\mu$ or $\kappa$ opioid receptors. Circulation 1998; 97: 1282-9.

7. Peart JN, Gross ER, Gross GJ: Effect of exogenous kappa-opioid receptor activation in rat model of myocardial infarction. J Cardiovasc Pharmacol 2004; 43: 410-5.

8. Wang GY, Wu S, Pei JM, Yu XC, Wong TM: Kappa- but not delta-opioid receptors mediate effects of ischemic preconditioning on both infarct and arrhythmia in rats. Am J Physiol Heart Circ Physiol 2001; 280: H 384-91.

9. Aitchison KA, Baxter GF, Awan MM, Smith RM, Yellon DM, Opie LH: Opposing effects on infarction of delta and kappa opioid receptor activation in the isolated rat heart: implications for ischemic preconditioning. Basic Res Cardiol 2000; 95: 1-10.

10. Wang J, Gao Q, Shen J, Ye TM, Xia Q: Kappa-opioid receptor mediates the cardioprotective effect of ischemic postconditioning. Zhejiang Da Xue Xue Bao Yi Xue Ban 2007; 36: 41-7.

11. Park SS, Zhao H, Jang Y, Mueller RA, Xu Z: $\mathrm{N}^{6}$-(3-Iodobenzyl)adenosine-5'-N-methylcarboxamide confers cardioprotection at reperfusion by inhibiting mitochondrial permeability transition pore opening via glycogen synthase kinase $3 \beta$. J Pharmacol Exp Ther 2006; 318: 124-31.

12. Wong TM, Lee AY, Tai KK: Effects of drugs interacting with opioid receptors during normal perfusion or ischemia and reperfusion in the isolated rat heart-an attempt to identify cardiac opioid receptor subtype(s) involved in arrhythmogenesis. J Mol Cell Cardiol 1990; 22: 1167-75.

13. Chang WL, Lee SS, Su MJ: Attenuation of post-ischemia reperfusion injury by thaliporphine and morphine in rat hearts. J Biomed Sci 2005; 12: 611-9.

14. Gross ER, Hsu AK, Gross GJ: GSK3 inhibition and KATP channel opening mediate acute opioid-induced cardioprotection at reperfusion. Basic Res Cardiol 2007; 102: 341-9.

15. Jang Y, Xi J, Wang H, Mueller RA, Norfleet EA, Xu Z: Postconditioning prevents reperfusion injury by activating opioid receptors. Anethesiology 2008; 108: 243-50.

16. Gross ER, Gross GJ: Ligand triggers of classical preconditioning and postconditioning. Cardiovasc Res 2006; 70: 212-21.

17. Peart JN, Gross GJ: Exogenous activation of delta- and kappa-opioid receptors affords cardioprotection in isolated murine heart. Basic Res Cardiol 2004; 99: 29-37. 